International Journal of Physical Sciences and Engineering
Available online at http://sciencescholar.us/journal/index.php/ijpse
Vol. 3 No. 1, March 2019, pages: $32 \sim 41$
e-ISSN : 2550-6943, p-ISSN : 2550-6951
https://doi.org/10.29332/ijpse.v3n1.254

\title{
Harmonics Influence on Power and Energy Measurements
}

\author{
Armando E. Garcia Trujillo a
}

Article history: Received 27 July 2018, Accepted: 31 December 2018, Published: 16 March 2019

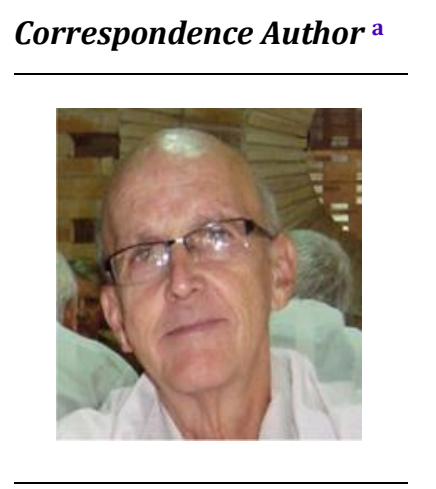

Keywords

energy control;

harmonics;

MATLAB simulation;

measurement;

nonlinear loads;

\begin{abstract}
To carry out the control and trade of electric energy, power and energy meters are used profusely. This article discusses the differences in the power and energy readings of the measuring instruments of different types and their use for the control of the quality of the supply and consumption of electrical energy. The contradictions of these readings are analyzed when measured in consumers of non-linear loads, generators of harmonics, and of linear loads, consumers of them. Simulation methods are used to show how harmonic propagation occurs in the system. MATLAB Simulink is used as a method of simulation with generating harmonics loads and linear loads. It analyzes how the parameters of the energy quality of the consumers can be affected and it is proposed to use the measurement of the active power of the harmonics as a means of control and penalization.
\end{abstract}

e-ISSN: 2550-6943, p-ISSN: 2550-6951 @ Copyright 2019. The Author. SS Journals Published by Universidad Técnica de Manabí. This is an open-access article under the CC BY-SA 4.0 license (https://creativecommons.org/licenses/by-sa/4.0/) All rights reserved.

\section{Contents}

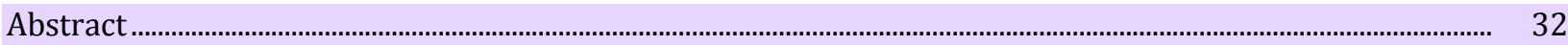

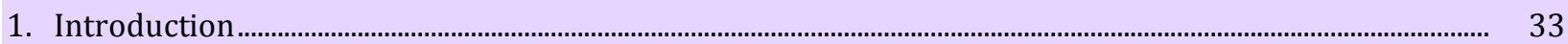

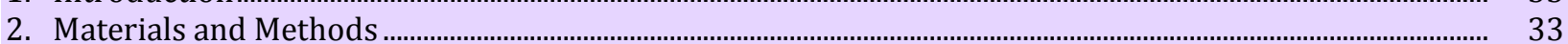

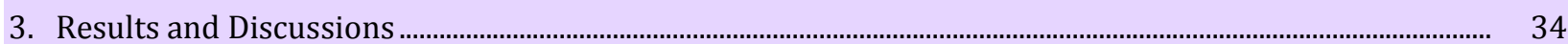

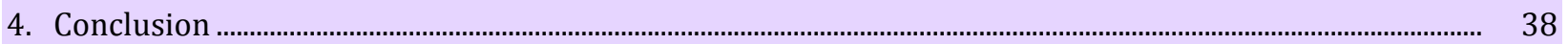

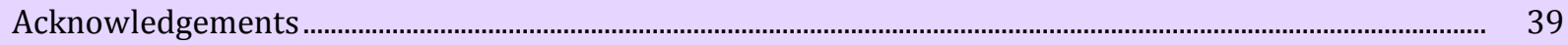

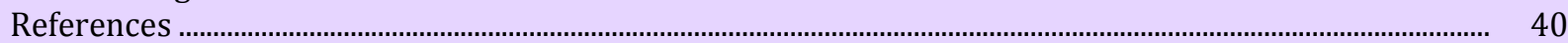

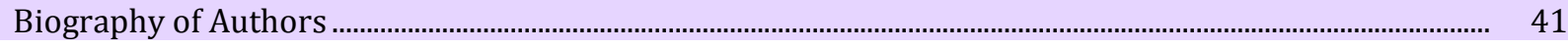

a Universidad Politecnica de La Habana, Cujae. Faculty of Electrical Engineering, La Habana, Cuba 


\section{Introduction}

Nowadays the use of equipment with non-linear characteristics is increased at all levels of electrical systems, both industrial and residential. The currents that take or deliver these loads are not sinusoidal and usually produce undesirable effects in the system or at least makes it behaves differently than anticipated in the original designs. Among the equipment affecting the waveform of the power supply current, Arrillaga (2003), mention the following:

a) Static converters (rectifier groups, speed controllers, static starters, battery chargers, etc.) - Singlephase electronic equipment (computers, printers, programmable automata, etc.)

b) Lighting installations with discharge lamps and LEDs.

c) Arc furnaces and welding equipment.

d) Transformers, ballasts with an iron core, etc., when working in the non-linear zone of the magnetization curve.

In recent years, the use of wind and photovoltaic energy has increased rapidly as alternative means providing a non-degradable and less polluting source of energy but using static converters that introduce harmonics in the system (Sierra et al., 2013).

In the case of lighting installations, mainly public streets and avenues, the discharge lamps are now more rapidly replaced by LED luminaries. These introduce a smaller content of harmonics, which helps to mitigate their effect in the system (Hossein et al., 2015). Another current trend is the large-scale introduction of electric transport, and it is significant that in some countries the total replacement of car fleet in cities is expected in a period of 10-20 years. Persson et al., (2017), assert that massive use of battery chargers at weak distribution points contributes with the dispersal of harmonics in the system.

The most important consequences of non-sinusoidal waveforms can be summarized in the following:

a) Overheating of transformers and distribution lines.

b) High currents and losses in the neutral of an installation.

c) Improper firing by an overload of overcurrent and differential relays.

d) High resonance currents through power factor corrector capacitors.

e) Disturbances in readings of the measuring instruments.

The circulation of non-sinusoidal currents by the distribution and transmission circuits causes voltage drops in transmission lines and transformer impedances, leading to a deformation of the voltage in circuits where these Impedances are not small enough. This is the reason why non-sinusoidal voltages and currents are observed in some consumers with linear loads.

For the study of this type of disturbances of the electrical systems, the decomposition in Fourier series of the non-sinusoidal waves is used. In this way currents and voltages are represented by the sum of a series of sinusoidal waves of frequencies multiples of a fundamental frequency with variable amplitudes and phases, generally decreasing.

This gives the possibility to analyze the circuit, in a first approximation, as a linear circuit and apply superposition for each different frequency source contained in the series.

For a particular circuit, it is possible to know in principle the generators and the consumers of harmonics knowing the type of load and measuring the harmonic content of the voltages and the currents of each one.

Currently, there are no electricity consumers without polluting loads and it is difficult to know if for a certain frequency the energy is consumed or generated by that load.

Although there is always the possibility to know if in a circuit there is circulation of harmonics by analyzing the connected loads and the impedance of the system, usually the analysis must be carried out from specific measurements of the amplitudes and angles of currents and harmonic voltages present in the system.

\section{Materials and Methods}

The Matlab was used for the design and influence of the harmonics on Power and Energy Measurements

Trujillo, A. E. G. (2019). Harmonics influence on power and energy measurements. International Journal of Physical Sciences and Engineering, 3(1), 32-41. https://doi.org/10.29332/ijpse.v3n1.254 


\section{Results and Discussions}

The measuring equipment to carry out measurements in electrical systems with the presence of harmonics uses acquisition and digital processing systems of data based on the algorithm of the fast Fourier transform. This results in the so-called amplitude and phase frequency spectra of the in-studio signals (Rojas et al., 2014).

The purchase and sale of electric energy are done through the indications of the energy meters located in the supply node of the consumers. Currently, all industrial consumers have electronic meters installed, which in addition to energy measurement give information on another series of parameters useful to know the behavior of the load.

However, there can still be three-phase induction type counters in industrial installations with the aim of internal control of energy consumption.

The following effects are observed in the induction energy meters:

a) An excess in the reading of the energy consumed by the non-linear loads with respect to the reading of the digital equipment.

b) A lower reading than digital equipment in linear loads.

c) These differences are mainly due to the limited frequency response of the induction counters. However, the interpretation of the results may be contradictory.

In the induction counter, the motor moment spinning the disc depends on the forces appearing by the interaction between the magnetic flow of the potential coil with the parasitic current of the current coil and the flow of the current coil with the parasitic current of the potential coil. The following effects are observed here:

a) To ensure that potential and current flows are at $90^{\circ}$ when the load PF is 1 , the potential flow is divided into two parts and one of them is offset by short-circuiting coils or metal sheets in the air gaps.

b) Frequency variations alter the distribution of flows by varying the reactance of the compensation coils resulting in a decrease and additional phase angle shift of the useful potential flow through the disc.

c) The impedances of the trajectories of the parasitic currents increase with the increase of the frequency.

d) As a result of these effects, an appreciable reduction of the motor moment is obtained with the increase of frequency.

The effects described making the energy meters based on the induction mechanism correctly measure the energy at the fundamental frequency ( 50 or $60 \mathrm{hz}$ ), have an appreciable error for second and third harmonics and practically do not respond for harmonics of greater order than 5 (Masri et al., 2017).

The electronic meters operate by taking a series of instantaneous values simultaneously of the voltage (U) and the current (i) in the load. Multiplying the corresponding voltage and current values, the instantaneous power values ( $\mathrm{p}$ ) are obtained. To obtain the active power (Pi) the average value of the instantaneous powers is calculated during a cycle. Active energy (E) is obtained from the sum of the multiplication of the active power by the interval of time $(\mathrm{T})$ between two samples of that power.

$$
\mathrm{P}_{\mathrm{i}}=\frac{1}{\mathrm{~N}} \sum_{1}^{\mathrm{N}} \mathrm{u} \cdot \mathrm{i}=\frac{1}{\mathrm{~N}} \sum_{1}^{\mathrm{N}} \mathrm{p}
$$

$$
\mathrm{E}=\sum_{0}^{\mathrm{t}} \mathrm{P}_{\mathrm{i}} \cdot \Delta \mathrm{T}
$$

$\mathrm{N}$ is the number of voltage and current samples for one cycle and $\mathrm{T}$ is the time during which the energy is measured.

The electronic meters can perform these operations in two basic ways (Persson, 2017):

a. Analog multiplication of voltage and current, filtering of the output voltage of the multiplier to obtain a DC voltage proportional to the active power, conversion of this to frequency and counting of the output pulses.

b. Digital analog conversion of instantaneous voltage and current values and perform operations of formulas (1) and (2) with the microprocessor. 
There are all kinds of variants of the previous methods depending on the type of analog multiplier, $\mathrm{V} / \mathrm{F}$ Converter, analog-digital converter and data processing, but all are governed by the same algorithm and if the frequency band of the elements or the number of samples per cycle is sufficiently high the power values of the upper harmonics can be recorded with good precision. It can be said that they indicate the actual value of the active power consuming the load whenever the source presents internal impedance sufficiently small.

In order to verify the behavior of the measured powers by the instruments and the power flows of the different harmonics in the network, the simulation is used under different load conditions and impedances in the circuit.

\section{Simulation}

A system where the supply source is free of harmonics and there are linear and nonlinear loads can be represented by the circuit of Figure 1 where Rs and Xs represent the impedance of the system.

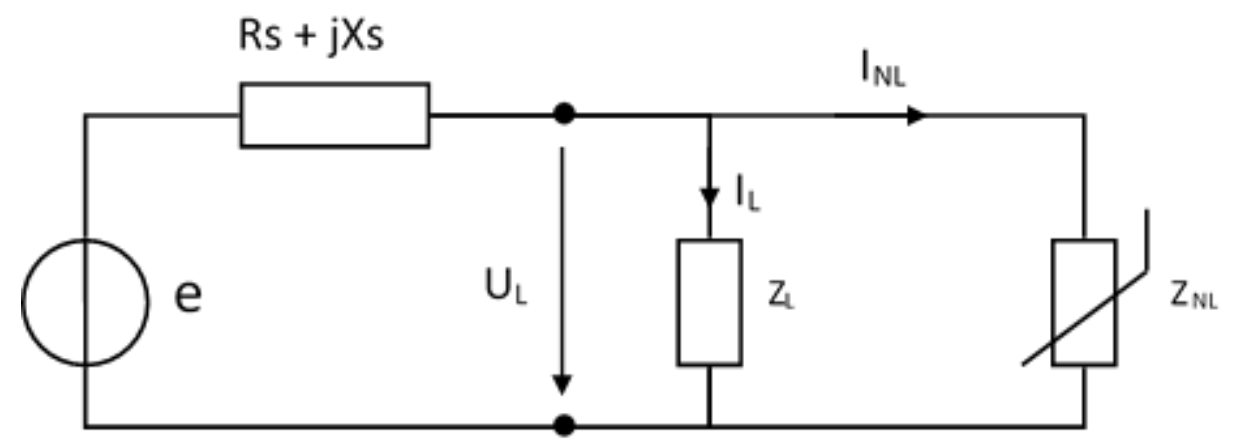

Figure 1. Circuit with non-linear load

The current flowing through the non-linear load is non-sinusoidal and causes the voltage in the UL common feeder to have higher-order harmonic components. This makes circulate current through the load ZL that will also contain harmonics of the same order as those present in the voltage of the feeder.

If you know the order, magnitude and phase of the harmonic components of the current INL can replace this load by as many sources of current as harmonics and applying superposition can analyze the propagation of the same by the system. Figure 2 shows a circuit formed by the linear load ZL, the impedance of the system Rs + JXs, the linear component of the non-linear load ZNL1 and as many sources of current as harmonics circulate through the circuit (Hasanuzzaman et al., 2016).

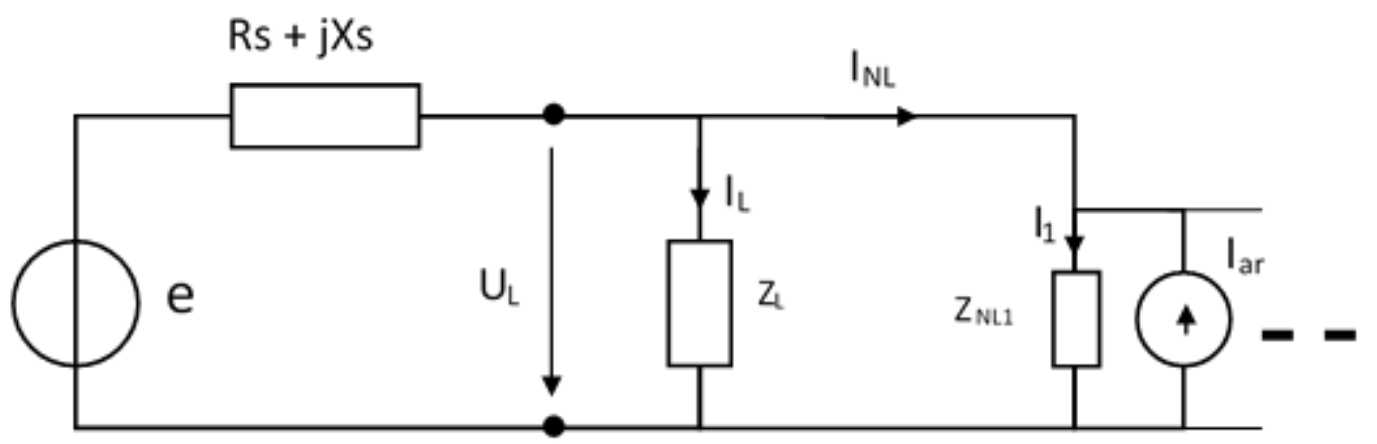

Figure 2. Equivalent circuit with harmonics current source

Trujillo, A. E. G. (2019). Harmonics influence on power and energy measurements. International Journal of Physical Sciences and Engineering, 3(1), 32-41. https://doi.org/10.29332/ijpse.v3n1.254 
first harmonic energy in a non-linear load.

In the linear load the energy of the harmonics caused by the deformation of the voltage is in the same direction as the main flow of first harmonic energy coming from the system and in this case, the total energy will be greater than that of first harmonic (Hasanuzzaman, 2016).

This explains the differences between the readings from induction counters and electronics. In the case of non-linear loads, the first ones measure the first harmonic energy and as they do not take into account the rest of the harmonics their reading is greater than that of the electronic ones. For linear loads, the reading of the induction counters is higher.

An interpretation from the point of view of the energy flow is that the nonlinear load receives the energy of the source of first harmonic and returns part of this energy in the form of harmonics to the system. This energy is consumed in other system loads and impedances and impoverishes the quality of the supply.

The norms generally provide limitations on the harmonic content of voltages and currents of consumers by means of harmonic distortion factors for voltage (THDV) and current (THDI). These standards are general recommendations and do not always force consumers to connect harmonic filters or compensators. In some load analyzers, the angle between the voltage and current harmonics is taken into account but cannot be defined if the energy is generated or consumed by the load (Masri, 2017). Petkovi \& Stevanovi (2014), proposes to use the measurement of the distortion power as an indicator of the presence of harmonics and to use that parameter as a penalty element.

In connection with energy consumption there are the following contradictions:

a. The consumer with a non-linear load that uses an electronic counter to measure the total energy, the more harmonics it delivers to the line less will be what it has to pay.

b. The consumer with linear load must pay the energy amount of the harmonics that come from other parts of the circuit and may cause inefficiencies in his system (García, 1985); ( Surendra, 2016).

To verify this was performed a simulation using MATLAB Simulink where for the non-linear load ZNL was used a three-phase converter of 6 pulses operating at $208 \mathrm{~V}$ line, with a power of $37.7 \mathrm{KW}$. Connected to the same common connection point (CCP), a 3-kW linear three-phase resistive load (about 12 times lower than non-linear) was placed.

The impedance of the system was considered as an inductance in series with the source of each phase. A multiplier with a low-pass filter is used to measure the total power of each load (Figure 3).

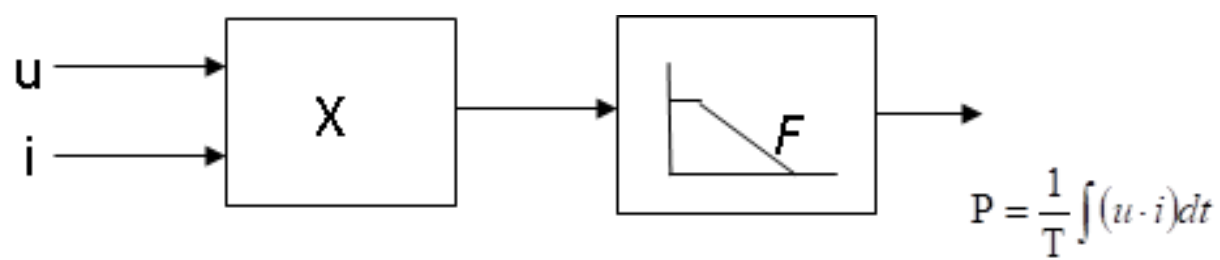

Figure 3. Simulation for total power measurement

The measurement of the active power by harmonics was made from the use of the Fourier block, at the output of the voltage and current meters. This element gives the module and the angle for the specified harmonic from the vector that is applied to the input (Figure 4). With this data, the effective values of the voltage and current with its angles are obtained for each phase. 


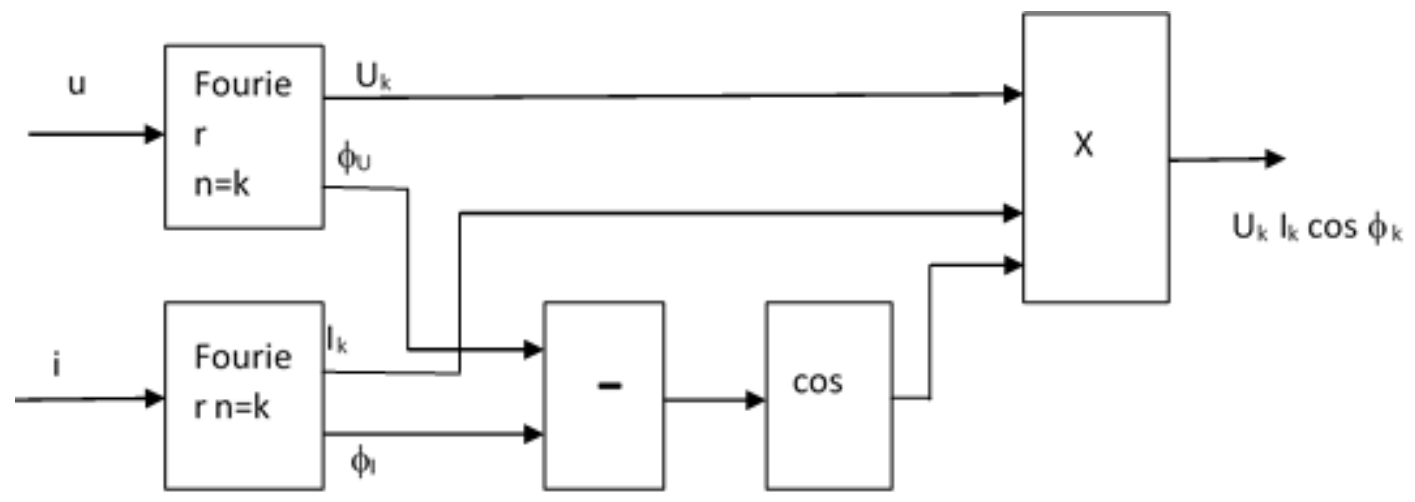

Figure 4. Simulation of $\mathrm{k}$ harmonic power measurement

Multiplying voltage by current and subtracting the arguments are obtained the powers for each harmonic for each phase. The sum of the powers of each stage gives the three-phase power of each harmonic that is shown in a digital display (Figure 5).

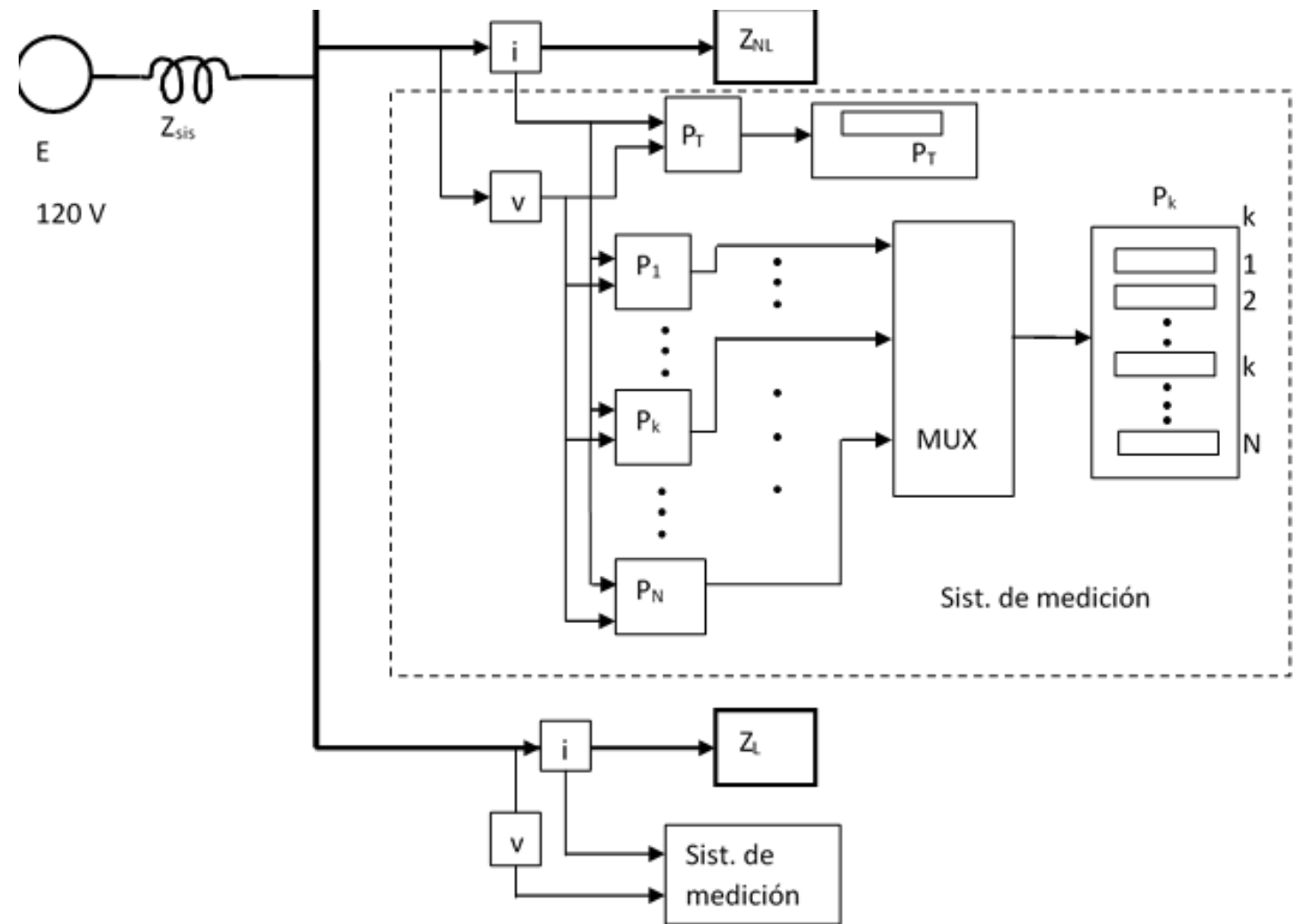

Figure 5. Simulation of the system with total power and harmonic measurement

The "v" and "i" blocks are the voltage and current meters required for the program to work. A similar measurement system is used for the linear load.

Runs of the program were carried out for different values of inductance of the power supply which makes vary the harmonics content of the voltage of the load feeder and therefore the distribution of the harmonic currents by the system.

Trujillo, A. E. G. (2019). Harmonics influence on power and energy measurements. International Journal of Physical Sciences and Engineering, 3(1), 32-41. https://doi.org/10.29332/ijpse.v3n1.254 
Tables 1, 2 and 3 show the total active power and harmonic values of each load in Watt for three generator impedance values.

Table 1

Total active power and harmonics power in of each load for Zsis $=0 \mathrm{mH}, \mathrm{UCN}=120 \mathrm{~V}$

\begin{tabular}{ccccccccccc}
\hline Load & $\mathrm{P}$ & $\mathrm{P}_{1}$ & $\mathrm{P}_{3}$ & $\mathrm{P}_{5}$ & $\mathrm{P}_{7}$ & $\mathrm{P}_{9}$ & $\mathrm{P}_{11}$ & $\mathrm{P}_{13}$ & $\mathrm{P}_{15}$ & $\mathrm{P}_{17}$ \\
\hline $\mathrm{NL}$ & 37718 & 37707 & 0 & $-0,32$ & 0,22 & 0,67 & 0,17 & $-0,14$ & 0 & 1 \\
$\mathrm{~L}$ & 3000 & 2999 & 0 & 0 & 0 & 0 & 0 & 0 & 0 & 0 \\
\hline
\end{tabular}

In table NL and $\mathrm{L}$ are the nonlinear and linear loads respectively and $\mathrm{P}$ the total active power.

In this case, it is observed that the source is ideal and at the load, feeder is applied a sinusoidal voltage equal value to the source. Because of this, all the power dissipated in the loads is first harmonic. The difference between the indications of the total power meters P and the first harmonic P1 is $0.03 \%$ for both loads. These are mainly due to program approximation errors and are not significant

Table 2

Total active power and harmonics of each load for Zsis $=0.5 \mathrm{mH}, \mathrm{UCN}=117 \mathrm{~V}$

\begin{tabular}{ccccccccccc}
\hline Load & $\mathrm{P}$ & $\mathrm{P}_{1}$ & $\mathrm{P}_{3}$ & $\mathrm{P}_{5}$ & $\mathrm{P}_{7}$ & $\mathrm{P}_{9}$ & $\mathrm{P}_{11}$ & $\mathrm{P}_{13}$ & $\mathrm{P}_{15}$ & $\mathrm{P}_{17}$ \\
\hline $\mathrm{NL}$ & 31233 & 31303 & 0 & $-39,6$ & $-21,7$ & $-0,8$ & $-4,65$ & $-2,81$ & 0 & $-3,08$ \\
$\mathrm{~L}$ & 2846 & 2766 & 0 & 38,5 & 22.5 & 0,07 & 4,62 & 2,63 & 0 & 2,5 \\
\hline
\end{tabular}

When appreciable inductance appears in the source the voltage in the feeder decreases and appears harmonics that produce dissipation of power. In the non-linear load the powers of higher order harmonics are negative, that is, it generates power of harmonics. In the linear load, these powers are positive and practically of the same value. There are differences between the total and first harmonic powers of the order of- $0.23 \%$ for the non-linear load and $+2.5 \%$ for the linear load.

Table 3

Total active power and harmonics of each load for Zsis $=1 \mathrm{mH}, \mathrm{UCN}=112 \mathrm{~V}$

\begin{tabular}{ccccccccccc}
\hline Load & $\mathrm{P}$ & $\mathrm{P}_{1}$ & $\mathrm{P}_{3}$ & $\mathrm{P}_{5}$ & $\mathrm{P}_{7}$ & $\mathrm{P}_{9}$ & $\mathrm{P}_{11}$ & $\mathrm{P}_{13}$ & $\mathrm{P}_{15}$ & $\mathrm{P}_{17}$ \\
\hline NL & 26019 & 26149 & 0 & -80 & $-30,6$ & $-0,1$ & $-7,3$ & $-7,1$ & 0 & $-2,44$ \\
$\mathrm{~L}$ & 2628 & 2490 & 0 & 79 & 31,3 & 0 & 7,2 & 7,3 & 0 & 2,79 \\
\hline
\end{tabular}

Increasing the inductance of the source is accentuated the effects of voltage drop and an increase of harmonics in the CCP. In the same way, the differences between the total and the first harmonic powers increase up to $0.49 \%$ for the non-linear load and $5 \%$ the linear load

\section{Conclusion}

To identify the loads that generate or consume harmonics, simultaneous measurements of current and voltage of each harmonic must be made and determine, through the angle between them or their multiplication, the direction of the power flow. Current load analyzers and energy meters must have this option among their functions.

A large consumer that generates harmonics may be working within the parameters that specify the standards in terms of their distortion factors (THDV or THDI) but may cause a harmonic content to another small consumer that makes it operate outside the Standard. It would be fairer to make the purchase of consumption through the energy of the first harmonic and not the total energy. That possibility is implemented in some energy meters. 
Although there are large current distortions if these are not reflected as voltage drops in the system impedances, there is no harmonic propagation. This happens with low impedances in the system and this condition is not always possible or economical.

With the increase of polluting loads in most consumers, it becomes difficult to know, without specific measurements, which are the harmonic generators and when this generation occurs. One way to force the harmonics producers to decrease them is to penalize the power or energy of harmonics that generate towards the system

Acknowledgments

The author is grateful to be able to carry out the research with the support of the faculty of electrical.

Trujillo, A. E. G. (2019). Harmonics influence on power and energy measurements. International Journal of 


\section{References}

Arrillaga, J., \& Watson, N. R. (2004). Power system harmonics. John Wiley \& Sons.

García A. (1985). Mediciones de potencia y energía como indicadores de la calidad de la energía eléctrica. Revista Ingeniería Energética. 1(85).

Hasanuzzaman M, Barczentewicz S, Bień A, Hanzelka Z.(2016). Localization of Harmonic Sources in Power System - Simulation and Laboratory Study.(2016). International Conference on Renewable Energies and Power Quality (ICREPQ'16). Madrid (Spain), 4th to 6th May, 2016. Renewable Energy and Power Quality Journal (RE\&PQJ) No.14 May 2016

Masri S, Mamat M, Yahya M. (2017). An Experimental Study of the Effect of Current THD to kWh Meter's Energy Measurement. (2017) International Journal of Innovative Research in Electrical, Electronics, Instrumentation and Control Engineering 5(2), February 2017.

Persson J, Watersström J, He Y. (2017). Measurement of Harmonics and Sags in Grid Voltage when Charging Electric Vehicles. 1s E-mobiliy Power System Integration Symposium. Berlin,Germany. 23 October 2017.

Petković, P., \& Stevanović, D. (2014). Detection of power grid harmonic pollution sources based on upgraded power meters. Journal of Electrical Engineering, 65(3), 163-168.

Pourarab, M. H., Nakhodchi, N., \& Monfared, M. (2015, June). Harmonic analysis of LED street lighting according to IEC61000-3-2; a case study. In Proc. CIRED Conf (Vol. 2015).

Rojas Cubides, HE, Rivas Trujillo, E., \& Jaramillo Matta, AA (2014). Technical and normative aspects for the monitoring and measurement of harmonics. Engineering (0121-750X) , 19 (2).

Sierra Gil, E., Coello Igarza, D., \& Pérez Lorenzo, A. (2013). Power quality in electricity networks with wind penetration. Case: Turiguanó Wind Farm. Energy Engineering , 34 (2), 98-107.

Surendra J. (2016). Harmonics in power system and metering.(2016). Secure Meters Ltd 2016 disponible en https://www.securemeters.com/index.php/insights-news/white-papers/ 


\section{Biography of Author}

\begin{tabular}{||l|l|}
\hline \hline & $\begin{array}{l}\text { Armando, } \\
\text { Received the B.Sc. degree in Electrical Engineering in } 1966 \text { at Havana University. } \\
\text { He carries out postgraduate studies on measurements at the Moscow Energy } \\
\text { Institute from } 1966 \text { to } 1968 . \text { Since } 1968 \text { he joined the Department of Basic } \\
\text { Electricity of the Faculty of Electrical Engineering, teaching the subjects of } \\
\text { electrical measurements. From } 1974 \text { to } 1978 \text { he worked as a technical advisor at } \\
\text { the Ministry of Foreign trade for the selection and evaluation of electrical and } \\
\text { electronic instruments. In } 1983 \text { he obtained the Ph.D. in technical sciences at the } \\
\text { Moscow Energy Institute. In } 1985 \text { he obtained the category of Titular professor. } \\
\text { Participates in research works of the Department of Basic Electricity and in the } \\
\text { industry such as the construction of prototypes of electronic energy meter, } \\
\text { transducers for the measurement of power, digital wattmeter. He has taught the } \\
\text { master's courses in automatic measurement systems in the 1998 to 2018 } \\
\text { mentions of the Master of Electrical Engineering in Cuba, Venezuela, and Bolivia. } \\
\text { Email: aegt@electrica.cujae.edu.cu }\end{array}$ \\
\hline
\end{tabular}

Trujillo, A. E. G. (2019). Harmonics influence on power and energy measurements. International Journal of 